\title{
Mapping Nurse Mobility in Canada with GIS: Career Movements from Two Canadian Provinces
}

Gavin J. Andrews, PhD

Professor, Department of Health, Aging \& Society, McMaster University

Hamilton, ON

Linda McGillis Hall, RN, PhD

Kathleen Russell Distinguished Professor

Lawrence S. Bloomberg Faculty of Nursing, University of Toronto

Toronto, ON

Sheri Price, RN, PhD

Assistant Professor, Dalhousie University, School of Nursing

Halifax, NS

Michelle Lalonde, RN, MN

Lecturer, Lawrence S. Bloomberg Faculty of Nursing, University of Toronto

Toronto, ON

Alexandra Harris, RN, MN, MBA

Graduate Student, Lawrence S. Bloomberg Faculty of Nursing, University of Toronto

Toronto, ON

Sandra MacDonald-Rencz, RN, MEd

Nursing Executive Advisor, Strategic Policy Branch, Health Canada

Ottawa, ON 


\begin{abstract}
Recent years have witnessed the publication of a growing number of studies of nursing which, from a disciplinary perspective, are geographical in their orientation. Conceptually, while the emphasis in much of this research has been focused at the micro scale on the dynamics between nursing and "place," curiously there has been scant attention to geometrical "space," and the basic yet important locational and distributive features of nursing at the macro scale. Noting this gap in the literature, the authors of this paper used a Geographical Information System (GIS) to map the movement of 199 nurses from two Canadian provinces where they were educated Manitoba and Newfoundland - to the provinces where they currently live and work. While the findings show that nurses who move tend to move to nearby provinces, more generally they illustrate the effectiveness of GIS for managing data and representing findings from workforce studies.
\end{abstract}

\title{
Background: The Geographical Tradition in Nursing Research
}

Nursing has always been geographically aware. Concerns with geographical concepts such as environment date back to Nightingale's early commentaries on heat, light, ventilation and air quality, from the scale of cities to the scale of rooms (Andrews 2003). Since the 1940s, the concept of nursing environment has emerged as one of the three core metaparadigms of the profession, influencing teaching and research for generations of nurses (Thorne et al. 1998). More recently, the focused development of a geographical tradition is identifiable through nurse researchers' drawing explicitly on the theories, concepts and methods of the discipline of human geography, and specifically the subdiscipline of health geography. Indeed, this latest research has become known as "the geography of nursing" or "nursing geographies" and has enriched and advanced both of its constituent fields (Andrews 2006; Andrews and Evans 2008).

Conceptually, much of the geography of nursing has focused qualitatively on "place." Places are understood in this research as more than locations or points, being complex social and cultural "fields of action" where people's lives unfold in certain ways, and where they gain unique experiences, attachments and identities. Practically, these can arise as hospital wards and community settings. A range of relationships have been articulated in the literature, including how places characterize particular professional subspecialties of nursing (Cheek 2004), how places of nursing possess symbolism and are sometimes contested (Gilmour 2006) and how places affect the outcomes of focused clinical interventions (Hodnett et al. 2005). Further studies have addressed the impact of different places upon nurse- 
patient interactions and relationships (Malone 2003; Bender et al. 2010), upon inter-professional interactions and relationships (Liaschenko et al. 2011) and the embeddedness of clinical practice in localized communities (Skelly et al. 2002) and natural environments (Watterson et al. 2005).

Curiously, however, far fewer studies in the geography of nursing have drawn on the other fundamental geographical concept of "space" (Endacott et al. 2009; Graves 2009). Indeed, in human geography, contemporary understandings of space originate in a positivistic tradition dating back to the 1950s. Here, space has been viewed as an underlying template for all human agency, as neutral surface on which life unfolds. It is a template given meaning - representing substantial features of human life - when "things" such as people, facilities or political boundaries are located in it. Space then becomes mathematically distinguishable and dividable. While at one level rates, volumes and other measures become visible at points, at another level times, distances, movements and differences become visible between points. Indeed, the reason space is handled in this way in human geography is a belief among scholars that it is possible to find spatial patterns in collective human existence - some of humankind's fundamental and underlying "geometries."

Although there are numerous examples of using a Geographical Information System (GIS) in health research to represent mortality, morbidity and health inequalities (Mitchell et al. 2002), access to services (Martin et al. 2002) and health needs (Gibson et al. 2002), less GIS work has been undertaken within nursing. Specifically, a number of discussion papers have brought the potential of GIS to nurses' attention and have identified challenges with its use (Caley 2004; Endacott et al. 2009; Graves 2009). From an empirical perspective, nurse researchers have used GIS to show community health states and the utilization of health services (Caley 2004; Faruque et al. 2003) and workforce distributions in the context of specific recruitment and retention initiatives (Courtney 2005).

From the perspective of the nursing workforce, many geographical studies have focused on the spatial features of career movements, along with the cultural, social and economic forces that shape them at local (Brodie et al. 2005), national (Baumann et al. 2004) and global (Kingma 2005) scales. Nevertheless, mirroring this broader conceptual absence, the treatment of space has been partial in that only one study has actually attempted to map these movements (Courtney 2005). Thus, acknowledging that "space matters," and using a GIS analytic approach, the current study has two objectives: first, to utilize maps to demonstrate nurse mobility across two Canadian provinces; and second, to showcase GIS as a research tool and reflect upon its application in this empirical context. 


\section{Method}

Originating in early computer cartography, GIS is a comprehensive technology for collecting, storing, retrieving, analyzing, re-analyzing and displaying spatial information. Categories of information that can be plotted and mapped by GIS include densities and clusters, rates and single-point distributions of phenomena. For the current study, the GIS software package ArcView 10.1 GIS was used to reveal patterns, relationships and trends in nurse mobility. Survey data were inputted into the GIS software and digitized or geocoded by postal code, a process of linking geographical coordinates and mapping these in an accessible and ascetic form.

Selected quantitative data obtained through a survey of 2,675 Canadian registered nurses (RNs) and licensed practical nurses (LPNs) who migrated across Canada for work were utilized in this study. Survey results are presented in the previous paper (McGillis Hall et al. 2013) and other papers in this Special Issue. The data presented in this paper are from respondents originating in Manitoba $(n=76)$ and Newfoundland ( $n=123$ ); they highlight the migratory movement of these nurses from the province or territory $(\mathrm{P} / \mathrm{T})$ of initial education (origin) to that of their current employment (destination). The data are converted by the GIS software into maps for each of the provinces, with lines generated from the origin to the destination $\mathrm{P} / \mathrm{T}$. The density of the line in each of the maps reflects the number of nurses who migrated.

Data from these two particular provinces were specifically selected because initial analysis confirmed that they provided the best opportunity to show patterns of nurse mobility at the regional level. Indeed, because of the space required to present and analyze GIS maps, it is typical for journal articles to focus in detail on a limited area, the full national or international picture often emerging across multiple journal articles or in research reports and other longer publications.

\section{Results}

Findings can be shown using traditional tables or as GIS maps. Table 1 presents data from nurse participants in this study indicating that nurses who moved from the two provinces were more likely to go to a nearby province. Specifically, of the nurses who were first educated in Newfoundland, $82 \%(n=101)$ went to the four closest provinces - New Brunswick, Nova Scotia, Prince Edward Island or Ontario, all of which are in east-central or eastern Canada. Only 18\% $(n=22)$ moved farther afield. Closer analysis revealed that over half $(54 \% ; n=67)$ stayed within the three neighbouring Atlantic provinces - New Brunswick, Nova Scotia or Prince Edward Island. Similarly, of the nurses moving from Manitoba, 83\% $(n=63)$ moved to the three nearest provinces - Alberta, Ontario or Saskatchewan, while only $17 \%(n=13)$ moved beyond. Likewise, over half $(58 \% ; n=44)$ stayed within the Prairie provinces of Alberta and Saskatchewan. 
Table 1.

Mobility patterns of nurse participants from Newfoundland and Manitoba

\begin{tabular}{|c|c|c|c|}
\hline $\begin{array}{c}\text { Source Province/ } \\
\text { Territory }\end{array}$ & $\begin{array}{c}\text { Destination Province/ } \\
\text { Territory }\end{array}$ & Number (\#) & Percentage (\%) \\
\hline \multicolumn{4}{|l|}{ Newfoundland } \\
\hline & Ontario & 34 & 27.6 \\
\hline & New Brunswick & 32 & 26.0 \\
\hline & Nova Scotia & 25 & 20.3 \\
\hline & British Columbia & 10 & 8.1 \\
\hline & Prince Edward Island & 10 & 8.1 \\
\hline & Alberta & 8 & 6.5 \\
\hline & Manitoba & 4 & $3 \cdot 3$ \\
\hline & Total & 123 & 100 \\
\hline \multicolumn{4}{|l|}{ Manitoba } \\
\hline & Alberta & 26 & 34.2 \\
\hline & Ontario & 19 & 25.0 \\
\hline & Saskatchewan & 18 & 23.7 \\
\hline & Quebec & 8 & 10.6 \\
\hline & British Columbia & 5 & 6.6 \\
\hline & Total & 76 & 100 \\
\hline
\end{tabular}

The GIS maps illustrate these moves in a more visual manner, as presented in The GIS maps illustrate these moves in a more visual manner, as presented in Figures 1 and 2.

\section{Figure 1. Manitioan nusen nobility map}

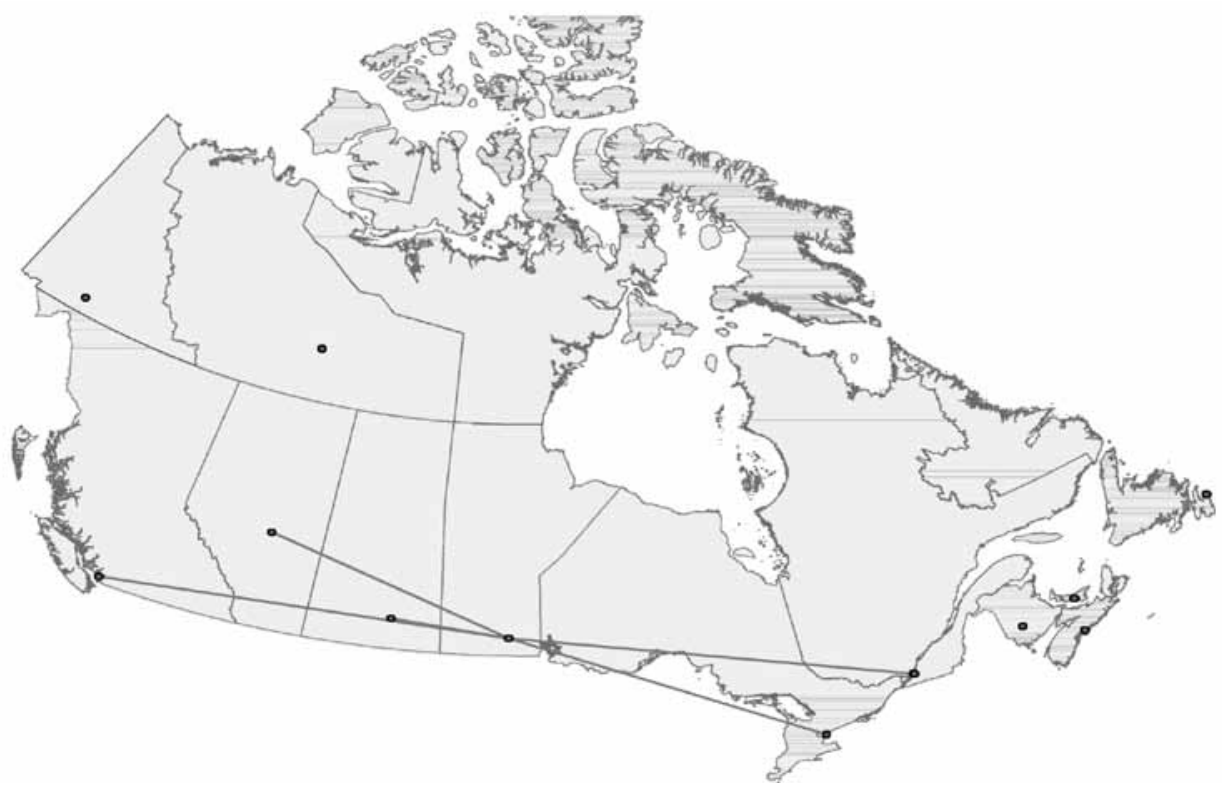




\section{Figure 2. Newfoundand nuse moblity map}

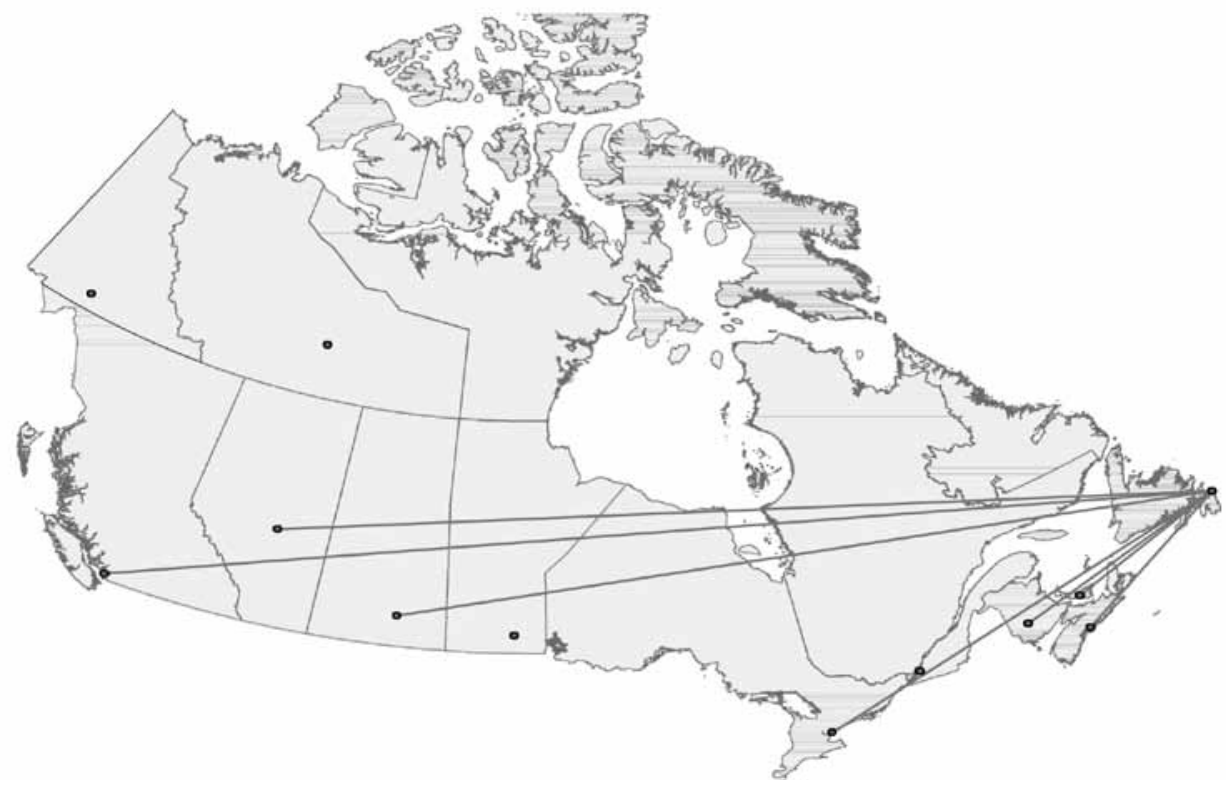

\section{Discussion}

Showing nurse migration data in table form gives the reader exact figures on trends and descriptive statistics such as volumes and percentages. Indeed, in this format, the findings are provided in both a comprehensive and "purer" form. However, use of GIS maps adds something different and significant, namely a visual representation of locations, distances and overall distributions, all of which are not available in a tabular format. Maps are particularly valuable for international readers who might not be familiar with the scale of another country or the relative positioning of its political borders. Moreover, even readers who live in or are familiar with a particular country might benefit from an immediate visual representation of it.

No map can ever be a true representation of an area or place, for all maps contain some thematic or structural bias and, in the end, are only representations themselves. However, they do reflect and convey, to some extent, what is happening "out there" on the ground, in a manner less abstract than tables and other forms. Notably, maps are also quicker and easier to read than tables and are far more interesting. The lines, colours and visions of places people know draw the reader's attention and beg to be inspected. In short, not only do GIS maps show things other approaches do not, because of their ease and look they are less likely to be ignored.

The results found in this GIS analysis reinforce findings identified in earlier quantitative reports on nurse mobility suggesting that regional mobility in the labour 
market takes place in some areas of the country, including eastern and western Canada (Baumann et al. 2004; CIHI 2010). Thus, the utility of adding GIS to traditional quantitative data analysis is confirmed.

\section{Implications}

Many scholars hold the view that the application of GIS in health research has made geographical approaches appear more useful to mainstream medicine and the health sciences, providing geographical information that helps with decision-making, policy analysis and evaluation. This sense of usefulness is further enhanced by the wider "spatial" turn in the health sciences, itself connected to the emergence of the social model of health and an acknowledgement that disease, health and well-being are strongly rooted in factors that lie outside the receipt of medicine, in communities and the broader environment.

It is of course problematic to make broad summary statements about any type of approach in research, GIS or otherwise. Each approach has its own strengths and weaknesses, and each can be applied in different ways. In the current study, although GIS provided valuable insights into the study of Canadian nurse mobility, there were also limitations. For example, had the data been available to the research team, the study could have benefited from a more refined GIS analysis, such as exploring to which parts of provinces nurses moved. In addition, it is unknown whether nurses' current destination province is representative of their sole move for employment, or merely the most recent. In terms of scope, this research paper describes nurse mobility between two provinces, and cannot be considered representative of the mobility patterns of nurses from all $\mathrm{P} / \mathrm{T}$ in Canada. Further attention is required to moves from all Canadian $\mathrm{P} / \mathrm{T}$ in order to gauge how unique the two provinces considered are, and to obtain an overall picture of the Canadawide situation related to nurse mobility.

More generally, the study illustrates the potential of GIS to inform health human resources planning and decision-making. Indeed, decision-makers often value information that is clear, that quickly presents a picture and thus is able to inform, and help build, a compelling argument. Of course, significant challenges remain with further developing GIS in nursing. Currently, most GIS training and analysis services are provided for nursing by geography, epidemiology and other academic units. Indeed, a next step is for nursing to develop its own "in house" GIS expertise through dedicated training and infrastructure, so that GIS becomes an established and common tool of nursing research.

\section{Conclusion}

Overall, the exercise of using GIS demonstrated how insightful the technology can be in large-scale workforce studies in nursing. Combining the results of a GIS 
mapping approach with those reported in quantitative and qualitative surveys provides the opportunity to develop a more comprehensive understanding of nurse mobility. Moreover, in terms of disciplinary perspectives it showcases how, as well as taking place seriously in the area of "geographies of nursing," space might also be afforded the attention it rightly deserves, and the locations, directions, distances and distributive features of nursing explored and articulated. These spatial features visible at the macro scale provide important contexts that help set up complementary qualitative place-based analysis at the micro scale.

\section{Acknowledgements}

This study was funded by the Canadian Foundation for Healthcare Improvement and Health Canada's Office of Nursing Policy.

The authors would like to thank Lorraine Dales, RN, MN, former research officer, Lawrence S. Bloomberg Faculty of Nursing, University of Toronto, for her assistance with this study.

Correspondence may be directed to: Gavin Andrews, PhD, professor, Department of Health, Aging \& Society, McMaster University, Kenneth Taylor Hall, Room 240, 1280 Main St. West, Hamilton, ON L8S 4M4; tel.: 905-525-9140, Xt. 26390; email: andrews@mcmaster.ca.

\section{References}

Andrews, G.J. 2003. “Nightingale’s Geography.” Nursing Inquiry 10(4): 270-74.

Andrews, G.J. 2006. “Geographies of Health in Nursing.” Health and Place 12(1): 110-18.

Andrews, G.J. and J. Evans. 2008 "Understanding the Reproduction of Health Care: Towards Geographies in Health Care Work." Progress in Human Geography 32(6): 759-80.

Baumann, A., J. Blythe, C. Kolotyloe and J. Underwood. 2004. Building the Future: An Integrated Strategy for Nursing Human Resources in Canada - Mobility of Nurses in Canada. Ottawa: Nursing Sector Study Corporation.

Bender, A., G.J. Andrews and E. Peter. 2010. “Displacement and Tuberculosis: Recognition in Nursing Care." Health and Place 16(6): 1069-76.

Brodie, D., G.J. Andrews, J.P. Andrews, G. Thomas, J. Wong and L. Rixon. 2005. "Working in London Hospitals: Perceptions of Place in Nursing Students' Employment Considerations." Social Science and Medicine 61: 1867-81.

Caley, L. 2004. "Using Geographic Information Systems to Design Population-Based Interventions.” Public Health Nursing 21(6): 547-54.

Canadian Institute for Health Information (CIHI). 2010. Distribution and Internal Migration of Canada's Registered Nurse Workforce. Ottawa: Author.

Cheek, J. 2004. “Older People and Acute Care: A Matter of Place.” Illness, Crisis and Loss 12(1): 52-62.

Courtney, K. 2005. "Visualizing Nursing Workforce Distribution: Policy Evaluation Using Geographic Information Systems." International Journal of Medical Informatics 74(11): 980-88.

Endacott, R., K.B. Maged, B. Manning and I. Maramba. 2009. "Geographic Information Systems for Healthcare Organizations: A Primer for Nursing Professions." CIN: Computers, Informatics, Nursing 27(1): 50-56. 
Faruque, F.S., S.P. Lofton, T.M. Doddato and C. Mangum. 2003. "Utilizing Geographic Information Systems in Community Assessment and Nursing Research." Journal of Community Health Nursing 20(3): 179-91.

Gibson, A., S. Asthana, P. Brigham, G. Moon and J. Dicke. 2002. "Geographies of Need and the New NHS: Methodological Issues in the Definition and Measurement of the Health Needs of Local Populations." Health and Place 8(1): 47-60.

Gilmour, J.A. 2006. "Hybrid Space: Constituting the Hospital as a Home for Patients." Nursing Inquiry 13(1): 16-22.

Graves, A. 2009. "A Model for Assessment of Potential Geographical Accessibility: A Case for GIS." Online Journal of Rural Nursing and Health Care 9(1): 46-55.

Hodnett, E.D., S. Downe, N. Edwards and D. Walsh. 2005. "Homelike versus Conventional Institutional Settings for Birth." Review. Cochrane Database of Systematic Reviews 1: 1-38.

Kingma, M. 2005: Nurses on the Move: Migration and the Global Health Care Economy. Ithaca, NY: Cornell University Press.

Liaschenko, L., C. Peden-McAlpine and G.J. Andrews. 2011. "Institutional Geographies in Dying: Nurses' Actions and Observations on Dying Spaces Inside and Outside Intensive Care Units.” Health and Place 17(3): 814-21.

Malone, R. 2003. "Distal Nursing." Social Science and Medicine 56(11): 2317-26.

Martin, D., H. Wrigley, S. Barnett and P. Roderick. 2002. "Increasing the Sophistication of Access Measurement in a Rural Health Care Study." Health and Place 8(1): 3-13.

McGillis Hall, L., J. Peterson, S. Price, G. Andrews, M. Lalonde, A. Harris et al. 2013. "I Was Never Recruited: Challenges in Cross-Canada Nurse Mobility." Canadian Journal of Nursing Leadership 26(Special Issue): 29-40.

Mitchell, R., D. Dorling and M. Shaw. 2002. "Population Production and Modeling an Application of Geographic Information Systems in Health Inequalities Research.” Health and Place 8(1): 15-24.

Skelly, A., T.A. Arcury, W. Gesler, A. Cravey, M. Dougherty, S. Washburn et al. 2002. “Sociospatial Knowledge Networks: Appraising Community as Place." Research in Nursing and Health 25(2): $159-70$.

Thorne, S., C. Canam, S. Dahinten, W. Hall, A. Henderson and S.R. Kirkham. 1998. "Nursing's Metaparadigm Concepts: Disimpacting the Debates." Journal of Advanced Nursing 27(6): 1257-68.

Watterson, A., A. Thomson, C. Malcolm, A. Shepherd and C. McIntosh. 2005. "Integrating Environmental Health into Nursing and Midwifery Practice." Journal of Advanced Nursing 49(6): $665-74$. 